\title{
Muslims and the State in Britain, France, and Germany
}

\author{
Joel S. Fetzer and J. Christopher Soper
}

Cambridge: Cambridge University Press, 2003. 208 pages.

The expanding Muslim communities in Western Europe have become a source of consternation in European capitals. Central to the issue of Europe's growing Muslim population is how far the secular state is willing to accommodate religious practices deemed to be antithetical to "European" values. Fetzer and Soper's timely comparative study effectively addresses the issue's historical foundations as well as clearly explains the European Muslims' disparate political responses.

The authors' central focus is how three core European states have accommodated the needs of Muslims flooding their borders since the 1960s. Exploring Europe's surprisingly disjointed response to Muslim immigration proves to be both theoretically interesting and an invaluable exercise in debating what options are available to elected governments that are being increasingly pressured by right-wing activism when it comes to accommodate the practice of Islam in Europe.

The questions raised in the book's six chapters, three of which are dedicated to the countries in question and the others to presenting the data collected via the authors' surveys, should prove helpful to larger discussions in European studies about what the contemporary dilemmas facing Germany, Britain, and France are in the context of the so-called war on terrorism. While most studies on Islam in Europe, particularly migration and gender studies, focus on how Muslims mobilize their socioeconomic resources, Fetzer and Soper contend that developing a public policy on Muslim religious (and political) rights is actually mediated in significant ways by the different institutional church/state patterns within each country.

This move away from the assumption that Muslims, if organized in the right way, could expect certain institutional concessions in "democratic Europe” proves to be a helpful intervention into a sometimes doctrinally 
rigid field of research. As this book demonstrates clearly in chapter 3, "France: Laïcité and the Hijab," although Muslims in France seem to be the most organized, they ultimately have proven to be the least successful in gaining concessions from the French government, which is eager to keep the secular state and its services separate from the religious communities' needs. It turns out that British concessions to Muslim community "rights" are far more generous, despite the fact that Muslims in Britain do not share the organizational competence and uniformity of their French counterparts.

While not explicitly stated, the authors' analysis of migrant politics in Europe does have some potential pitfalls. At times, they slip into the habit of reducing the "Muslim" to a generic category. As a result, they fail to acknowledge the existence of ethnic, doctrinal, national, economic, and linguistic divisions within Muslim communities that may contribute to the variable experiences that Muslims have with European states. While Fetzer and Soper are to be commended for appreciating factors that distinguish Muslims from each other, this persistent dose of reductionism may affect their conclusions. For example, when explaining why the reader must recognize the nuances of intra-Muslim relations in each country, the authors tend to stick to the clumsy term "Muslim community" throughout the book in order to make their sociological observations.

It sometimes becomes a frustrating exercise to try to decipher the authors' intentions when the analysis is so often reduced to treating British, French, and German "Muslims" as a categorically singular unit. Ultimately, this failure to remain sensitive to the varying factors that could account for the fact that all three countries host a fascinatingly diverse set of Muslim groups taints the value of the authors' conclusions.

It might have been more instructive, for example, to reflect on what accounts for the lack of political cohesiveness among Muslim communities in order to appreciate how state institutions, regardless of their capacity to accommodate varying interests, circumvent Muslim demands for equal access to state funds and institutions. For all of the British political establishment's efforts to address institutional restrictions to the practice of Islam, for instance, there is an equally valuable conclusion to draw from just who will become the acknowledged representatives of the British-based ummah when institutions are actually created.

By no means does the largely Pakistani/Indian Muslim diaspora depicted in this study accurately represent the varying interests in the larger Muslim experience(s) in Britain. The process by which some groups, nevertheless, become associated with British Muslims may help this study further. 
Likewise, the blanket application of "Algerian" and "Turk" in respect to French and German Muslim communities, respectively, fails to account for the vast range of generational and regional/cultural distinctions that these Muslims make as they socialize and organize politically. Further exploring the underlying distinctions that the Bosnian, Kurdish, Albanian, and Alevi Muslim communities make from their Berber or Turkish counterparts may contribute to communal failures to lobby the state successfully.

That being said, this study sheds a great deal of light on regional variances of applying state authority vis-à-vis Europe's Muslims when taking the perspective of Berlin, Paris, and London. The fact that they approach their Muslim migrant communities so differently in terms of accommodation (in Britain) to open restriction (in France), and with Germany somewhere in between, extends this study's value well beyond the narrow field of comparative institutional analysis or state/society relations. Therefore, it is a useful contribution for scholars wishing to make comparisons between Europe and other regions experiencing similar tensions as regards accommodation and state control. The book may also be appropriate for graduate seminars that want to explore a variety of case studies on Europe.

The narrative is crisp and economical, favoring at times a far-too-abbreviated style that tends to skip over issues that perhaps deserve more energy and time. This is especially true when the authors start to discuss the variables of doctrinal and cultural diversity among Muslims in these three countries. Nevertheless, the authors' well-argued conclusions deserve serious consideration. In the end, I suspect that their work will even inspire more detailed studies, perhaps as a result of concluding that while this study is valuable, it is, nevertheless, incomplete.

Isa Blumi

Assistant Professor, International Studies Department The American University of Sharjah, United Arab Emirates 